\title{
Thinking and listening: Understanding improvisation
}

\author{
Evan Desaulnier and Ellen Waterman
}

This manuscript was prepared under the supervision of Professor Ellen Waterman, School of Fine Art and Music, College of Arts.

\begin{abstract}
To anyone who has ever attended a concert of live improvised music, I would ask: "Wasn't there something about being there and witnessing the music unfold that somehow deepened your understanding of it?" The work that follows is the result of a seven month-long study that I conducted for my undergraduate honours thesis at the University of Guelph. My interest in the phenomenon of live improvised music has to do with the audience; for it is first as an audience member that I became fascinated with the way in which live improvisation meant more to me when I was immersed in its context: the performance event. The first goal of this study rests within developing an ethnomusicological research methodology that could be applied to field research in live improvisation. My research goals aim to discuss the social space of performance in improvised music and as such, considerable emphasis was placed on analysing the context of performance.
\end{abstract}

$\mathrm{T}_{\mathrm{i}}$ o anyone who has ever attended a concert of live improvised music, I would ask: "Wasn't there something about being there and witnessing the music unfold that somehow deepened your understanding of it?" Similarly: "What was it about the performance in particular that created such a sense of involvement and engagement?" These types of question could be turned on their heels and addressed to the improvising musicians as well: "Was there anything about performing in front of a live audience that affected what you played?" Questions of this sort all attempt to articulate the idea that there are certain contextual elements unique to the performance that affect our understanding of the music; elements that go beyond simply allowing audience members and musicians to see each other. There is something about being present at a performance of improvised music that allows individuals to participate in its creation in real-time, something that engages both its players and its listeners that begs to ask: "How are seeing and listening meaningful in the social space of performance?"

\section{BACKGROUND}

The work that follows is the result of a seven month-long study that I conducted for my undergraduate honours thesis at the University of Guelph. My interest in the phenomenon of live improvised music - aside from what it can offer me as a musician in terms of enjoyment and musical education has to do with the audience; for it is first as an audience member that I became fascinated with the way in which live improvisation meant more to me when I was immersed in its context: the performance event.
Two important issues need some clarification in order to discuss the nature of this study. First, by using the term creative improvisation I am referring to music in which the entire musical content or unfolding is improvised in performance. I do not mean to suggest that musicians do not begin with anything pre-given - certainly individuals bring with them their own personalised playing style (as I will elaborate upon later) as well as the influences of the history of the genre ${ }^{a}$ - but rather that there is a heightened degree to which the musical content is improvised. In Western classical music, even though the music is written (or, prescribed), there is a certain level of improvisation required of a performer in interpreting certain written elements. For example, an organist realising a Bach fugue or a violinist reading a Hayden string quartet must each negotiate the nuances of dynamic markings, articulations, and also the feeling or mood of a given piece. Even in North Indian classical music which is based on improvisation, there are rigorous parameters that influence a sarod player's choice of pitches and melodies in order to successfully improvise upon a given raga. My point here is creative improvisation differs from other forms of musical improvisation in that it does not begin with the same set of prescriptions. Rather, the basis of this sort of improvisation lies within the negotiation of personal interactions through music. George Lewis describes improvised music as,

[A] social location inhabited by a considerable number of present-day musicians, coming from different backgrounds and musical practices, who have chosen to make improvisation a central part of 
their musical discourse. Individual improvisers are now able to reference an intercultural establishment of techniques, styles, aesthetic attitudes, antecedents, and networks of cultural and social practice. $^{17}$

Secondly, I wish to clarify an issue pertaining to the listener. Throughout this study, I will be focussing on the audience as listeners and as co-performers in the performance of improvised music. However, musicians also take on this double-role as they are also listeners themselves. By using the term listeners, I essentially mean both the musicians and the audience. If there needs to be a differentiation between the two, I will refer to the audience-as-listeners simply as the audience.

\section{Methodology}

The first goal of this study rests within developing an ethnomusicological research methodology that could be applied to field research in live improvisation. My research goals aim to discuss the social space of performance in improvised music and as such there needs to be considerable emphasis on analysing the context of performance. In a performance of creative improvisation, audience members witness the unfolding of a creation in real-time. Audience members (and the performing musicians) become subjected to a multitude of meanings which derive from the sonic imagery and also from interactions with other bodies - both players and other audience members. In other words, the audience becomes engaged as participants, or co-performers, rather than just evaluators. There are also a number of other contextual performance elements that can encode both musical and social meaning. Factors such as venue, type of audience present, time of day, and function of performance (for example, ritual or entertainment) all affect the way that participants understand what they see and hear. In addition to context, the music itself should be another focus of attention. Unlike written musical traditions, such as Western art music, the creative essence of live improvisation resides in the interpersonal relationships between musicians that are negotiated through music in real-time. The musical analysis should then focus on the process of improvisation, that is the real-time musical exchange between players, rather than the final product of the improvisation. Since contextual elements play a large role in the understanding and unfolding (process) of a given improvisation, there emerges a constant dialogue between sound and context. In order to address the sound-context relationship, there is a need for a research model that is sensitive to such a relationship.

I have drawn largely from Regula Burckhardt Qureshi's model that she developed in her analysis of Sufi ritual music. ${ }^{20}$ This research paradigm takes into account the implications of sound and context, first examining them separately, and then together as a "sound-oriented and context-oriented" ethnomusicological analysis. ${ }^{20}$ In my study, I will be providing a detailed description of two performance events which I will label by their venue: Somewhere There and Thursdays at Noon Concert Series. This description will thoroughly assess contextual factors as well as the musical processes that pertain to each concert. I will be paying considerable attention to the behaviour of the audience and the improvising musicians as the performance unfolds.

I will present two main perspectives in attempting to address my research goals. The first perspective, the cognitive perspective, represents a background in cognitive sciences. This approach, although valid in itself, mainly serves to address cognition and perception on the level of the individual. While certain elements that make up this perspective may be derived from socially conceived theories, I will discuss the ways that it falls short of addressing the actual interaction between musicians and audience members in performance. To address this shortcoming I will present the body-narrative perspective that I believe takes into account the contextual factors that shape interpersonal relationships in the performance of improvised music.

\section{The Cognitive Perspective}

The cognitive perspective attempts to describe the inner functions of human cognition as it perceives improvised music. Here, I am presenting some themes from recent literature on musical improvisation that draws from trends in phenomenological philosophy, psychology, biological sciences, and ethnomusicology. This perspective discusses ways in which listeners (primarily musicians) perceive and understand the experience of improvised music.

\section{Musical Perception}

It is daunting to assess the depths of human perception that mediate a listener's understanding of sophisticated musical interactions in creative improvisation. The internal cognitive mechanism, which perceives and delineates complex, phenomenological stimuli, must first be understood before applying its principles to an analysis of music cognition. The following is a review of some recent interest in cognitive science as a means to describe the phenomenon of perception.

David Borgo describes the process of perception through a philosophical lens in borrowing the concept of qualia (singular: quale) from its use in phenomenological philosophy. Qualia represent an individual's subjective divisions of a continuous phenomenological experience (such as music), each having distinct qualitative values. ${ }^{5}$ More simply, qualia describe significant features of an experience. In music, this may refer to the timbre of a saxophone, or the tempo of a waltz, or even the intensity level of an entire group improvisation. Since qualia can refer to an endless number of features, their subjective 
qualities can become hierarchically organized, meaning certain qualia become more significant than others at a given moment in time. ${ }^{5}$ For example, while a listener may be focussing on a particular musical element (such as an interesting melody, the quality of a singer's voice, or the silence between symphonic movements) something new may emerge that shifts the listener's focus. The previous features that the individual was engaged with are not altogether forgotten, but they become subordinate to more immediate or more significant experiences.

Jared Burrows recognizes the notion of perception in improvised music as it relates to meanings that are produced as an improvisation unfolds. He argues that that the creation and the reception of an improvisation "constructs its own time-dependent meanings" that he refers to as musical archetypes. ${ }^{7}$ These archetypes comprise "generative or recurrent thematic" musical materials which play a role in the broader structuring of an improvisation in terms of emerging soundscapes. ${ }^{7}$ Furthermore, the meanings established by musical archetypes have collective as well as individual meanings. ${ }^{7}$ Individual meaning is constructed on the personal level, whereas the collective meaning develops as a result of group interaction. Consequently, improvisers can manipulate these meanings to create a dialectical sense of structure in which these meanings are embedded. ${ }^{7}$

There is a sense of similarity between Borgo's qualia and Burrows' concept of musical archetypes. They are both perceptive descriptions of sonic material that establish their own context-sensitive meanings and relationships. However Burrows' device differs in that it addresses the potential for a musical event to influence other parts of an improvisation. Simply put, the sounds that one musician makes affects what another plays, or the soundscapes that a group of improvisers explore at one moment will influence subsequent musical events. However, the term archetype implies that these emerging musical sign-posts carry an immutable set of meanings that (whether derived from sonic symbols or not) are continuous across different improvisations. Since meanings are context-dependent, it would seem that the use of the term archetype is inadequate. Moreover, while both qualia and archetypes are usefully employed to describe the perception of music, they do not address other situated factors in performance. Surely both audiences and musicians are aware of more than just sounds. In the space of performance, elements such as acoustics, visual representation of the musicians, and awareness of other bodies can not only affect how participants perceive sound, but also shape what it is that they perceive. That is not to say that the music is not central to a listener's attention, but that there are other elements in the context of performance that need to be taken into consideration in discussing perception.

Ed Sarath offers a model that delineates the process of perception and cognition in music. He refers to this mechanism as cognitive event cycles that occur in three parts, or conceptions: actuality, possibility, and probability. ${ }^{23}$ The first part, the actuality conception, represents the act of perception in which an improviser perceives a salient musical feature. The possibility conception results from the "field of implications generated from each actuality." 23 Importantly, the conception of possibility articulates the notion that sounds carry meaning to the improviser as a result of his or her own lived experience with music and society. ${ }^{23} \mathrm{~A}$ musician will internally generate a wealth of potential musical reactions in response to the perceived sound stimuli, the process that Sarath calls the probability phase. ${ }^{23}$

The concept of cognitive event cycles offers a systematic description of how musicians perceive and respond to musical stimuli. Significantly, Sarath draws from Paul Berliner's idea of a musician's history with music and society as an important factor in how he or she bases musical decisions. While this may speak to the social influence on music-making, it ignores the effect of context. Like Borgo and Burrows' accounts of perception, Sarath is only considering sounds as potential objects of perception, whereas many other performance elements can affect what musicians perceive. In addition to personal history, these contextual (and decidedly social) aspects need to be combined in order to address the interaction that occurs between performers during live improvisation.

\section{Temporality and Awareness}

Borgo and Sarath both draw from the phenomenological setting of time as it is laid out by philosopher, Edmund Husserl. In his terms, we "experience the flow of time as a continual 'sinking away' of present events into past" which is referred to as retention. ${ }^{5}$ Moreover, there is also a forward-looking component of our perception of time which Husserl dubs, protention, and it entails the anticipation of future events. ${ }^{5} \quad$ Sarath uses this view of time in his examination of temporality in improvisation. Improvisers experience time in an "inner-directed, or 'vertical' manner" which emphasises the localised present whereby the "past and future are perceptually subordinated." 23 To articulate this notion of the heightened present, Sarath denotes this innerdirected temporality as the primary level of conception in the improviser's state of awareness. ${ }^{23}$ Thus, there is also a subordinate level of conception, titled retensive-protensive temporality, and this mode of conception addresses the future-focussed component of Husserl's time perception, as well as the ability to perceive the immediate past, or sinking away of time. $^{23}$

Sarath's model, although a seemingly valid partitioning of a dynamic cognitive mechanism, was constructed in order to contrast ideals of awareness in improvisation with those found in compositional practice. Whereas this model works well in comparing the two musical systems, it falls short when examining one in exclusion of the other. When applying the notion of primary and subordinate levels of conception to improvisation, it seems erroneous to attribute such a discrete partitioning to the fluid nature of conscious 
thought. Even though Sarath mentions that inner-directed and retensive-protensive temporality are not necessarily mutually-exclusive entities, without the need for method comparison it is redundant to regard the two as distinct processes. I would argue that the conception of time within the improviser meshes more appropriately with Husserl's initial parameters. This means that there is essentially one single level of conception that focuses on the localised present as it progresses into the immediate past (retention) while constantly looking to the future (protention). The key difference here is that retensive and protensive strategies are not regarded as subordinate and unified properties, but rather as constantly functioning mechanisms which can both operate at different strengths. In this model, improvisers have a continual focus on the present with a constant memory of the immediate past, but can also employ future improvisational strategies as they have a constant, albeit varying, anticipation of future time coordinates.

\section{Heightened Awareness}

Intrinsic to the discussion of temporality and music perception as a whole, is the awareness state of the improviser, and also that of the listening audience. Most importantly, this facet of live performance entails a feeling of heightened consciousness and receptiveness within its participants. $^{2}$ The mercurial nature of this musical happening makes it particularly difficult to describe, and as a result it has been presented in a number of different lights. Groove, sync, peak experience, and flow are among the accepted metaphors for this process which all attempt to describe the causality and also the euphoric quality of this heightened state of awareness.

Berliner and Monson both utilise the concept of groove in their interpretations of heightened consciousness in performance. ${ }^{\mathrm{b}}$ This positions the process as an occurrence whereby a group defines and maintains "a solid rhythmic ground for their musical explorations" as a means of framing an emerging improvisation. ${ }^{2,18}$ This shifts the focus of the concept to an interactive quality within a group, which could definitively be perceived by an attentive audience. The collective groove would then also locate itself within the improvising individual, as each contributor to the groove experiences a sense of personal transcendence as well.

Borgo describes a biological construct that he names sync in an attempt to assess the phenomenon by which organisms can operate in synchrony with one another. His biologically-based standpoint differs from the concept of collective groove in that it extends beyond the discussion of a synchronised human interaction solely on the basis of a common rhythmic feel. For Borgo, "the process of listening to music together can [...] bring audiences and performers into neural synchrony as cognitive, perceptual, and motor constructs all may be engaged together.",

Others believe that psychology would better explain the phenomenon of heightened consciousness since it is a product of the human condition and realisations of the self. ${ }^{23}$ The works of Sarath and Csikszentmihalyi and Rich both cite psychologist Abraham Maslow's humanistic concept of peak experience. ${ }^{10}$ Sarath explains peak experience, or heightened consciousness, in terms of his organization of temporal awareness in improvisation. He postulates that the intensely inventive and creative state which is invoked through heightened consciousness is a product of self-reference or rather "the folding of awareness back toward itself." 23 This can occur when the improviser cognitively deconstructs temporal associations to the object-referral state of the ordinary, personal self and "sheds the bonds which confine awareness to localised, ordinary present consciousness and invokes a self-referral, heightened conception." 23 There is then a shift from the personal self to the unbounded self which enables heightened consciousness, and ultimately a degeneration of the improviser's conception of past-presentfuture relationship which is supplanted by an overarching, "eternal sense of presence.",23

Csikszentmihalyi and Rich depart from Sarath's decisively structuralist explanation of heightened consciousness, proposing instead a more systems-oriented take on the experience. ${ }^{10}$ Sarath's entire inquiry positions the mind as a detached processing machine rather than a participant in an ecological system that operates in response to more than just raw musical stimuli. Csikszentmihalyi and Rich designate the term flow as the descriptor of heightened experience. The notion of flow is manifested in the so-called micro level of creativity which 'involves a person's ability to innovate while interacting mentally with the rules or practices of a domain, while keeping in mind the judgments and practices of the field." 10 The domain represents the paradigmatic set of symbols that informs a discipline (for example, mathematics or music), and the field is indicative of the social element in the systems approach that evaluates the conventions of a domain. In addition, conditions that are favourable to the onset of flow allow for "a balance between the opportunities for actions (challenges) and the person's ability to act (skills)" in which the individual receives immediate feedback from their actions. ${ }^{10}$ In music, when an individual receives positive feedback from a knowledgeable audience, he or she is likely to experience flow.

Each of these perspectives offers valid points in describing the concept of heightened consciousness, but they each have decidedly different ways of addressing the influence of contextually-dependent factors in live improvised music. Sarath's in-depth take on cognition addresses the inner-mechanism of cognitive perception of awareness, yet it fails to account for the factor of social interaction that is present in the performance of improvised music. Borgo and Csikszentmihalyi \& Rich, although widely differing in background, do recognize the social factor that is implicit in performance, yet they do not incorporate the contextually-dependant factors that influence the personal interactions in live improvisation. The 
perspective that does in fact address the notion of performance context is that of Berliner and Monson. Essentially, the cognitive perspective is geared towards discussing how a musician can perceive and respond to musical stimuli, but this is not adequate for an analysis of an interaction between audience members and musicians in improvisation. The overlap here resides in Berliner's and Monson's contextually-situated approach to describing heightened awareness, or musical groove. This approach points to the importance of the body-narrative perspective as a suitable analytical means for discussing the personal interaction of improvised music in performance.

\section{Case Studies}

I attended and conducted field research at two performances of creative improvisation in the later portion of my thesis study period. The first performance took place on February $19^{\text {th }}, 2008$ at Somewhere There, a venue for creative music in Toronto, Ontario. The second concert that I studied was one of the instalments of the Thursdays at Noon Concert Series at the MacKinnon Building on the campus of the University of Guelph, Ontario on March $6^{\text {th }}, 2008$. At both of these performances, I videotaped the musicians on stage as well as the listening audience using two separate video cameras. In addition, I administered a survey form to the audience at each event. These short questionnaires asked simple, broadly-based questions that were accessible to individuals of any musical ability or familiarity. The survey questions were crafted to assess the audience's perception of the performances, and specifically what individuals listened to and looked for, as well as what stood out to them the most. Moreover, the questions were intentionally general in order to allow the audience members to answer in terms of whatever musical or visual elements they valued, in effect to create as little bias as possible. At Somewhere There, I had the opportunity to interview two of the musicians involved in the performance, trombonist Scott Thomson and guitarist Michael Keith. In this interview I asked questions about what sorts of concepts or ideas they keep in mind while improvising, how they collaborated (improvised) with other musicians, and also how they were aware of the audience while performing this particular show. At the second study, due to time constraints I was unable to interview any of the musicians at the performance; however, I was fortunate to conduct an interview that asked similar questions via e-mail with drummer, Joe Sorbara. The details of the interview and survey findings will be discussed after I provide a critical description of each study.

\section{Somewhere There}

The performance event at Somewhere There comprised two sets of improvising duo ensembles. The first set featured Thomson and alto saxophonist John Oswald who were then followed by Keith and his collaborator, David Sait who played the Chinese zither instrument, the qin. The formal layout of the evening's events, in my opinion, speaks to the function of the music - in other words how the music is viewed by both the musicians and the audience.

Somewhere There is a concert venue devoted to improvised music as well as other forms of creative musicmaking. The physical layout of the venue is that of a small loft setting that offers couch and chair seating on one side of the room, and an open space for performing musicians on the other. There is no elevated stage; the audience and the musicians are at the same level in an intimate performance environment. This concert in particular was attended by a small number of paying patrons who sat comfortably and listened. The majority of the audience were musicians themselves; in fact, when the musicians who were playing on stage, they sat amongst the audience. All of the audience members remained through both sets, only a couple individuals arrived once the concert began.

The first set began, not with any sort of formal introduction, but rather when Oswald sat down with his saxophone. Even before he was joined by Thomson, in what initially looked like a warm-up, Oswald began improvising on his saxophone with the intent to start his set. When Thomson eventually joined him a good while later, Oswald's sound fluidly meshed with Thomson's. The two improvisers, who played continuously for almost an hour, began to produce a wealth of unconventional sounds and sound gestures which took the form of guttural growls, pops, and low vibrating tones - just to name a few. Both of the players sat in stationary positions, occasionally shifting their body weight and angling the bell of their horns to create more contrasting sounds (generally). To add to their exploration of the sounds that their instruments were capable of producing, Thomson periodically chose from an array of mutes that were at his side. These ranged from traditional trombone mutes to other less conventional objects, such as a water bottle that he forced into the bell of his instrument while he was playing. What became strikingly apparent was that the duo was capable of negotiating a wealth soundscapes through their extending of instrumental technique. The two musicians seemed to coordinate their breathing as they both took breaths at the same time, creating interstitial silences within the unconventional soundscapes.

The second set, the one belonging to Keith and Sait, started in a similar way. Even though they were given a brief introduction between sets, once they sat down, they began to play - not through a rehearsed or cued beginning but rather once their bodies reached their instruments. Like the first group, they also improvised continuously for the entire duration. Given the different instrumentation present in this set, this duo sounded nothing like Thomson and Oswald. However, their process was similar in that, they too negotiated subtle shifts in sound texture as a primary means of interaction. Since Sait and Keith both played stringed 
instruments, their improvisation relied on the nuancing of the plucked string. Sait often scraped the strings of the qin while Keith plucked out sparse, heavily distorted pitches on the guitar, which he manipulated using the various guitar effects pedals at his feet. As the improvisation progressed, Sait began to play pitches which he bent by depressing the strings on the opposite side of the bridge. Keith interjected pitched bends on the guitar which were surrounded by a low growling drone that he achieved with one of his pedals. Like the first group, their bodies were more or less stationary, except for when Keith turned his torso and bent over to manipulate settings on his effects pedals. The improvisation gradually decayed in intensity and volume after about 45 minutes and the musicians sat in silence and relaxed their bodies before the audience applauded.

There was a sense of informality in both performances. Both sets began rather unexpectedly since the musicians began to play when they sat down with their instruments. Furthermore, not only did the musicians sit amongst the audience when they were not playing, but they chatted casually from the stage area between sets. The audience members, who were in relaxed positions on the couches, sat quietly throughout both of the sets. Each member sat still, as though deep in concentration. Certain members nodded their heads, suggesting that they were enjoying what they heard. The only times that the audience applauded were after they were certain that either performance was complete. They patiently waited in silence for the musicians to relax and put down their instruments in order to be sure that the given performance was in fact over.

\section{Thursdays at Noon Concert Series (TAN)}

This performance was a trio ensemble that featured visiting artist, Malcolm Goldstein on violin, accompanied by flutist Ellen Waterman, and of course, Joe Sorbara on drums. The format of this performance was in three parts: the first featured Goldstein on solo violin and spoken word, who was later joined by Sorbara on the hand-drum. The remaining two pieces were creative improvisation by all three musicians.

The venue here is an important descriptive element since it not only shaped the performance space in the physical sense, but it also influenced the type of audience that attended the concert. This performance took place in a large room in the music wing of the MacKinnon Building on the university campus that doubles as both a classroom and recital hall. The audience sat a considerable distance from the stage, positioned uncomfortably in the awkward seating that the room offers. However, this room was the site of the Thursdays at Noon Concert Series which was a 40-year-old series of regular performances that take place every Thursday at noon-hour during the fall and winter semesters. This concert series, which was entirely funded by the university, offers a wide variety of musical performances which range from Western classical music, to various world music traditions, and also to new and creative forms of music. Since these performances occur between noon and $1 \mathrm{pm}$, university students and staff members may attend between classes, and members of the community may attend the concert during their lunch-break. This performance in particular ran until slightly after $1 \mathrm{pm}$, so there were a few members of the audience who left early in order to arrive at classes or workplaces on time.

Throughout the performance, the musicians engaged in a highly physical interaction which seemed to be greatly informed by the sounds that they were producing. Goldstein began with a partially composed piece, in the sense that it had basic preconceived elements (three separate movements and scripted poetry) although the realisation of these elements was obviously improvised. From the outset, Goldstein began to loosely move his violin around his shoulder as he played melodic passages that he punctuated with dissonant double-stop ideas, screeches, and sharp, percussive bowing. As he began the poetry, he generally would quieten his playing and soften his physical gestures, only to return to the aggressive punctuations as before, which he then began to accompany with bodily swaying and bends of his torso. He continued in this manner until he looked at Sorbara, who was sitting patiently with drum in hand. Once the two musicians began to play together, they effortlessly collaborated in dramatically raising and lowering the dynamic intensity while bringing new ideas into their playing. Sorbara extended his hand-drumming technique by striking all areas of the drum and his thighs. The piece began to build in intensity until it abruptly came to halt as Goldstein made one final dramatic bow of the violin, aggressively thrusting his forearm into the air.

After an immediate applause from the audience, the duo was then joined by Waterman for the next two improvisations. The trio waited in silence until they each began to contribute short, quiet bursts on their instruments and all three musicians gradually engaged in bodily movements as they began to play. Goldstein launched his body into crouches and sways of his torso that corresponded to punches and screeches that he made with his instrument. Waterman alternated between vocal soundings and flute playing that she punctuated with thrusts of her knees as the three players began to build in intensity. As interaction, the three players often converged on high pitches or sustained tones that created a resounding dissonance - Sorbara achieved this by using a bow on the edges of his cymbals. Additionally, the three players built and took away from the dramatic intensity by dropping in and out of the soundscape. Waterman and Goldstein often took turns in silencing themselves. The piece ended with a cymbal roll by Sorbara which he quickly muted when his band mates ceased their playing. As it seemed to be understood by the performers 
that this signalled the end of the piece, the performers' bodies stopped moving and after a few seconds of silence, the audience soon also made this connection and applauded.

The third, short piece also featured the three musicians who incorporated this manner of kinetic relationship to their instruments. While many of the musical elements and interactions were similar, this piece relied more on sustaining long tones. While all three players frequently converged on their use of this device, the improvisation ended with one sustained note on from Goldstein's violin, and their bodies once again ceased moving.

The behaviour of the audience, as well as the way in which they related to the musicians in the performance venue, can help to describe the function of this music. Like the Somewhere There concert, from the start, or rather before the start of the concert, there was a certain air of informality to the performance. As the audience milled in, Goldstein stood on stage in front of them while warming up with his violin. Once he finished warming up, he did not disappear to later make a grand entrance; rather, he sat in the audience where he was eventually joined by Waterman before the concert began. Later on, between pieces, he made joking remarks to an audience member when her cell phone beeped. In terms of audience behaviour throughout the concert, the apparent informality by no means implied a lack of respect or reverence to the music - the audience appeared to be attentively listening. They were all quietly engaged with the performance and seem to be focused on the particularities of its unfolding. Certain members began to nod their heads at some points, suggesting that they were not only enjoying the music, but were thoroughly immersed in it.

\section{The Social Space of Performance}

The performance event, when considered as a social space, offers insight as to how it engages its participants - both musicians and audience members - in the social process of music-making. Simon Frith realises the connection between music and how it constructs social identity, or rather, music as identity,

Identity is not a thing but a process - an experiential process which is most vividly grasped as music. Music seems to be a key to identity because it offers, so intensely, a sense of both self and others, of the subjective in the collective. ${ }^{13}$

Effectively, the minute elements that make up a performance play a role in establishing a social sense of time and place one that becomes context-dependent. In a performance of improvised music, it is necessary to consider the performance elements that are unique to its process.

\section{The Body and the Narrative}

The occasion of a live performance of creative improvisation brings with it the presence of the human body as the creator of music, as a participant in music-making. In certain traditions the importance of the performer as the creative activator of music is downplayed. For example, in the performance of a Western classical symphony, the composer is widely viewed as the creator of the music as it is he or she who writes the score. Subsequently, performers are positioned as mere interpreters rather than the sources of the music itself. In creative improvisation, the body is an integral part of the music-making process as it is not only a site that generates meaning, but it is also an important contributor to the musical interaction. I will discuss the role of the body as it relates to the construction of the human self, as well as the personal and group narrative in music. Furthermore, I will also examine the effects that the live performing body has on participants in the improvisation on both musicians and audiences.

\section{Constructing the "Self"}

The human self is a social construction that is greatly informed by the body. Anthony Giddens states that "the self [...] is embodied" and that "the body is thus not a simple 'entity', but is experienced as a practical mode of coping with external situations and events." 29 Borgo and Iyer recognize the significance of this phenomenon as they posit complementary viewpoints that express the role of embodiment in musical improvisation. At the heart of either viewpoint resides the notion that the body cannot be separated from the mind in the perception and actuation of music. 5,15 Borgo elaborates a post-structuralist or systems logic that "encompasses not only the notions that our ideas, emotions and actions are all grounded in, and informed by, our bodily selves, but also [...] that the boundaries of the human 'self' are in fact constructed rather than given." Iyer cites neurological findings in his support of this concept, positing that motor output is the chief product of the human nervous system in that "all areas of the brain seem geared to coping with their functions as they pertain to problems of motor control."15 Thus, the system of the mind is informed by the functioning of the body as it interacts with its environment. At the same time, the boundaries of our bodily selves are not pre-given in terms of anatomical limitations, but are rather shaped by our experiences with an external reality. More precisely, the self is shaped in the social realm though an individual's interactions with society.

\section{Narrativity}

On the level of the musician, each musical utterance evokes a potentially infinite wealth of connotations and cultural associations within its listeners. Reciprocally, these musical 
ideas carry introverted meaning which the improviser cultivates as a result of his or her individual musical background and lived experience. ${ }^{3}$ The outward manifestation of this inner dialogue expresses an evocation of musical personality - a musical sense of self as a result of personal history with both music and society. Social theorist, Ian Burkitt examines the development of personality as a "socio-historical relation of the individual to the physical world, mediated by the labour process, but also through relations to other human beings which are mediated through language." If this sentiment is then applied to the construction of personality in music, it would support the notion that the musical self, or personal narrative, is constructed through an individual's musical and social interactions. ${ }^{\mathrm{c}}$ Furthermore, this concept can be widened to expand beyond the social construction of narrativity on an individual level to assess its collective effect as well. Group interactivity and the "encoded exchange of personal narratives" are both important contributors in the social dialogue that emerges. ${ }^{15}$ Given its varied forms of operation, I believe that it is necessary to discuss the notion of narrativity in terms of its individual manifestations, as well how it emerges in a group interaction.

\section{Personal Sound}

A significant aspect of the individual narrative resides in the formation of one's own concept of musical sound. In this sense, musicians are capable of establishing a coherent musical voice that creates their own continuous standard for musical decision-making. A player's accumulated experiences with life and music are eternally connected to his or her own sense of personhood in creating this kind of musical vocabulary. For George Lewis,

\begin{abstract}
"'Sound,' sensibility, personality, and intelligence cannot be separated from an improviser's phenomenal (as distinct from formal) definition of music. Notions of personhood are transmitted via sounds, and sounds become signs for deeper meaning beyond pitches and intervals."
\end{abstract}

In performance, these personalised sounds can exist as "not only timbre, but also articulation, phrasing, rhythm, melodic vocabulary, and even analytical methods." 15 In effect, an individual is selective of these devices and can "apply them uniquely according to each individual's temperament, personal style" and specific improvisational goals. ${ }^{3}$ It can be inferred that this sense of personal sound is reproducible and can be recognizable across different improvisations. Thus on the individual level, musical personality is locally dialogical. I am suggesting that the personalising of musical choices is not only a socially-informed process, but it is also evaluative, in that musicians must weigh their initial conceptions against the outward effect of these musical choices.

\section{The Body and Sound}

The musician's body, in addition to mediating a social construction of the self, further influences the personal narrative as a result of its physical connection to the instrument. As each player may have a different bodily approach to how they play their instrument - that is, ways in which they use their bodies to create sound - their bodies essentially leave an imprint on the qualities of the personal sound itself. ${ }^{15}$ Throughout the TAN concert, Goldstein attacked his violin with a highly physical bowing technique. He accompanied this motion with a dramatic shifting of his torso as he leaned his body into each attack. In doing so, his bow struck all over on the violin strings, sometimes coming in contact with the bridge. Not only did the generated sounds smack of this aggressive articulation, there was an audible variation in over-tones as a result of the positioning of his bow on the violin strings. While this example illustrates how a highly physical approach to the instrument can affect a player's sound, then what of a musician who is more reserved in bodily motion? If the relationship of the body to the instrument leaves an imprint on an individual's personal sound, then perhaps it is perceivable in other ways. At the Somewhere There performance, during Thomson and Oswald's set, Thomson frequently exhaled heavily into the trombone. Sometimes it is created a discernable pitch, other times it was simply the breath on its own. Oswald's exhales were also audible as he articulated notes with a long, airy build-up. Also, throughout their improvisation they appeared to breathe in unison in certain passages, with coinciding breaks for breath followed by simultaneous re-entries into their playing. The imprint of their bodies became apparent through an audible relationship of their bodily presence their breath. Certainly as wind players they were breathing when they were creating sound (apart from percussive noises on the instrument), but the presence of their breath as distinct from its use in the traditional playing technique cites the presence of the body through sound.

\section{The Body on Stage}

The presence of the music-making individual can visually encode personal narrative and process throughout an improvisation. As Susan Fast discusses, bodily stage presence creates a performance, or a fictional body. ${ }^{d}$ The ways in which a performer positions or moves his or her body on stage creates a theatrical projection of the body that can generate meaning. ${ }^{12}$ Additionally, "meaning is also located in the ways in which improvisers situate their bodies, change their facial expressions, and use their voices to accompany notes, gestures, silences, or phrases." 21 These ideas seem to suggest the notion of performativity. That is, there is additional meaning which results from contextual factors (in this case, the body) in addition to the meanings that are generated from the music itself. ${ }^{15}$ 


\section{Group Narrativity}

Given that certain aspects can be perceived by participants, the individual narrative qualities of both personal sound and bodily presence can affect the progression of a given improvisation. More specifically, the exchange of personal narratives becomes a "crucial role of interactivity and group interplay in the dialogical construction of multiplicities of meaning." 15 The very essence of creating a sense of individuality through sound, as we have seen, implies that it can be recognized, and as such can be anticipated to a certain extent. For Thomson,

"If I'm playing with someone for the first time, I'm negotiating the sounds they're making. But the sounds that they're making are ultimately secondary to who they are as people and they're communicating real things about themselves through the music they're making. [...] I'm not that interested in the sounds that [John Oswald] is making as ends in and of themselves; they are [...] very clear embodiments of who he is and I hear him, [...] who he is through the saxophone."25

Thomson's statement supports the importance of the exchange of personal narratives in improvisation. For him, it provides the means by which an interaction can take place. The sense of narrative exchange also implies that musicians may establish a sense of familiarity with each other through music. As Keith points out,

"I've played with [Sait] quite a lot so [even though] I never know what to expect when we play [...] I probably know that I'm going to be comfortable and not have trouble.",25

As a result of the exchange of narratives, a group narrative emerges on two levels: that a given improvisation is the result of an interaction of personal narratives, and also that the collective improvisation creates a sense of directionality, or narrative arc as it unfolds.

It could also be possible to predict or at least have a way of understanding an improviser's playing by visually assessing their physical actions. On a visual level, players can further communicate with each other through gestures, eye contact, and other overt cues which are meant to direct a given group interaction. For example, towards the end of the first improvisation at the TAN concert, while Goldstein was playing he looked to Sorbara in order to signal him to begin playing the hand-drum. Both personal sound and embodied actions further contribute to establishing a group sense of narrativity, since the personal narrative values of all of the contributing musicians are combined in producing their collective work. ${ }^{7}$ Definitively, this group narrative is contextually situated as it is a real-time musical development that comprises the unique intentions, bodily actions, and skills of its participants.

\section{The Audience as Performers}

I have briefly described their behaviour in performance, and I have provided some personal testimony from the audience in support of my claims about the dynamics of the performance context, but this does not exactly articulate what the audience is actually doing - that is, how they are participating. How does the audience perform listening in live improvised music?

The audience, both as a collective and as individuals, performs in two general ways: firstly, what they are doing that is, thinking and listening; and secondly, how they influence the performance in terms of their bodily presence and their interactions with the performing musicians. To address the thoughts of the audience, I will of course refer to the responses I gathered from the survey forms. From the Somewhere There concert, I collected 2 survey forms and from the larger audience at the TAN performance, I received 21 responses. According to the surveys from both concerts, most of the audience members were musicians - out of 23 surveys, only 5 individuals identified themselves as nonmusicians. Additionally, of 23 musicians, 20 of them stated that they played improvised music, or at least had previous experiences with musical improvisation. In order to discuss the audience interaction as it occurred in either of the performance events, I will also look to personal accounts from the musicians involved.

Based on the responses from the survey forms that I distributed at both of the performances, there was a large amount of highly descriptive feedback. The depth of the answers ranged from the very general to the highly specific some responses even mentioned musical events with respect to elapsed time. In their responses, audience members effectively addressed their observations, values, and expectations. Several recurring themes emerged: musical techniques, bodily gestures and expressions, the interaction of musicians, and also the witnessing of the social process (being present in the performance space). Since most of the survey forms that I collected were in response to the TAN performance, most of the testimonies that follow will reference that concert.

Many audience members make specific reference to the usefulness of being able to see improvising musicians play in order to be able to locate the source of certain unconventional sounds. While this held true for both of the case studies, in the TAN concert, there was a considerable number of responses that stated that visual information aided in understanding the sounds that came from the drum kit, "Particularly percussion [stood out] - technique and variety clarified by the visual." At the TAN concert, Sorbara made use of a variety of unconventional percussion techniques, 
such as using a violin bow to play cymbals and drumsticks that were rested across his drum heads. Even though there were a lot of references to Sorbara's extended drum techniques, there seems to be no correlation between responses from musicians (or improvising musicians) and their understanding of these techniques. That is, both musicians (with or without experience in musical improvisation) and non-musicians seemed to be equally interested in such unconventional techniques. Furthermore, there was also interest in seeing the performers' bodily connection to their instruments, according to an audience member, "seeing how the performers move [...] and how they relate to their instrument is very important to me." The visual component here seems to help listeners understand the unusual soundscapes that emerged in both performances.

The visual presence of the performers informed the audience about process as well. The audiences of either performance event could come from a wealth of different musical backgrounds and experiences and as such, visual representations of the process would be of great use.

Many of the responses attest to the notion that emotional meaning is encoded by the live performing (improvising) body. Here, the visual representation of the body is perceived by individuals in the audience who generally view this factor as being enriching or informative as they are able to sense the expressivity of the performers.

"Goldstein is an incredibly visually expressive performer who communicates much of the emotion of the piece through his facial cues and body language. My experience of the music was enhanced by this."

Also, "being able to see the emotions of their work though body movements and facial expressions [was one element that really stood out to me]."

Here, the body is performing emotionality. In the TAN concert, the performers' expressive bodily gestures were connected to the sounds that they were producing. With each sound came an associated gesture or bodily movement. For instance, Waterman's aggressive accents on the flute brought with them a thrust of the knee or a shift of the torso. Moreover, Sorbara's body did not cease in rhythmic motion until the trio had finished playing altogether. In terms of facial cues, the three performers all had serious, seemingly focussed expressions which were then relaxed once they ended each piece. I would argue that their bodies' performativity of expression are also communicating each player's musical intention through bodily motions. Furthermore, this musical intention ultimately speaks to an individual player's personal narrative, in that they are expressing personhood; they are expressing their emotions through both the sounds and bodily gestures that they are producing.
The performance event as a social space affected the way participants understood the music, or rather the process, and this was well articulated by the audience. In reference to the Somewhere There case study, one audience member stated that,

"This space is about performance but the emphasis is on the music [...] It's not really about seeing the musicians play. It's about being in the same room and feeling the trains of thought as they are being developed."

At this concert, all of the musicians were seated and, in comparison to the highly physical performance at the TAN concert, were relatively subtle in their body movements. However, a similar sentiment was experienced by an audience member within the space of the TAN performance where performers were highly active.

"To be honest, I would very rarely listen to music like that on a $\mathrm{CD}$, but experiencing it live is very enriching. Even a video wouldn't be the same because it's about moving in space and vibrational energy."

These audience responses illustrate that participating in the process - the act of listening and being present - goes beyond the visual (although there are a wealth of meanings that associate with visual representation). This evidence supports that the presence of the body in the space of performance, whether it be physical or social, or both, creates a sense of participation. It suggests that it is in experiencing the process and bringing bodies into proximity that brings forth such an experience.

The effect of the proximity of bodies also permeates the musicians' interactions onstage. In a sense, the collective presence of the audience can affect the unfolding of the performance. Musicians are aware of this factor and tend to describe it in terms of feedback that they receive from the audience. Joe Sorbara mentions that,

"You can tell when an audience is listening, when they are invested in the music-making process - and you can tell very much when they aren't. [...] If they are really invested, the sound moves in a big circle and the music has a kind of energy that feeds back into itself in a very organic flowering sort of way.",22

Scott Thomson also mentions the concept of feedback in describing his awareness of the audience in performance,

"I can feel everyone in the room [and] the music changes. And to describe what that change is: it's 
kind of a feedback that is intangible. It has to do with a kind of energy that comes through, it's the feedback of attention and really there's no way to describe that feeling [...] There's that sense of things moving outwards and feeding back in a complementary way." 25

The notion of audience feedback is the result of the audience's collective bodily presence in performance. In looking to both the TAN and the Somewhere There concerts, the audience behaved in similar ways. Each audience member sat silently, seemingly meditative of the unfolding performance. Some members leaned towards the performers, intently listening, some nodding their heads slightly, and others simply sitting perfectly still. The only applause or noise-making of any kind occurs between a given improvisation. This suggests that the complex interaction that occured between the audience and the performers occurs on a very subtle level. Even though the audience is actively thinking and listening, there is a dialogue of energy that occurs, as evidence from Sorbara and Thomson as well as audience members who describe their presence in the performance space (above). The audience is performing as listeners as they attentively sit in silence and provide this feedback, while also engaging themselves with the social space as well as the bodies around them.

\section{CONCLUSION}

This study relies most effectively on the use of the bodynarrative perspective as opposed to the cognitive perspective. The advantages of the former result from the practical use of social means to discuss social constructions. Using contextually-dependent elements such as the body and its effect on the narrative, more accurately addresses questions that pertain to context. Since the goal of this study was to discuss the interactions between musicians and audience members, something that only occurs in the context of performance, these contextually-dependant elements become the most useful tools. However, the cognitive perspective is not without its merit. It is not an inferior analytical device, rather it is geared to addressing a different set of research questions - questions that relate to an individual's cognitive perception of music, rather than the dynamics of interactions between individuals. As I have discussed, the concept of heightened awareness can draw from social influences, as seen in the work of Monson and Berliner. There is also mention of socially informed concepts in Sarath's cognition argument as well as in Csikszentmihalyi \& Rich's concept of flow despite the fact that they overlook context. Effectively, there is some overlap between the cognitive perspective and the body-narrative perspective, although it would be impossible to combine the two without radically revising one or the other.

\section{ENDNOTES}

${ }^{\mathrm{a}}$ The notion of genre in creative improvisation can be troubling, especially in comparison to other forms of musical improvisation such as jazz (both traditional jazz and modern, or "free" jazz). Like jazz, it can be easy to decide what does conform to the genre, but much more difficult to discern what doesn't belong. For instance, it would be hard to differentiate between free jazz and certain forms of creative improvisation in terms of sound alone. Thus, the lines on which to draw the boundaries of genre (if possible here) lay within more socially conceived characteristics such as the influence of community, and the historicity of the idiom (in terms of precursors to the genre, and also that of significant contributions to it by musicians). An accurate discussion of these factors falls beyond the scope of this project, so for my purposes I am going to use the description of creative improvisation as outlined above.

b Berliner and Monson's concept of groove stems from the work of Keil and Feld (1994)

${ }^{\mathrm{c}}$ Iyer frames the personal narrative as an exploded, holistic entity as a result of this complex social dialogue (2004).

${ }^{\mathrm{d}}$ Fast borrows this term from Eugenio Barba in his discussion of the theatricality of the body on stage as opposed to how it exists in everyday life (Fast, 146). ${ }^{\mathrm{e}}$ I point this out as a means of comparison between the two concerts. I do not wish to imply that there was anything less meaningful to see.

\section{REFERENCES}

1. Akinson, Paul et al. Key Themes in Qualitative Research: Continuities and Change. New York \& Oxford: AltaMira, 2003.

2. Beament, James. How We Hear Music: The Relationship Between Music and the Hearing Mechanism. Woodbridge: Boydell, 2001.

3. Berliner, Paul. "Give and Take: The Collective Conversation of Jazz Performance." Creativity in Performance. Ed. R. Keith Sawyer. Greenwich \& London: Ablex, 1997. 9-42.

4. Berliner, Paul. Thinking in Jazz: The Infinite Art of Improvisation. Chicago \& London: $\mathrm{U}$ of Chicago $\mathrm{P}$, 1994.

5. Borgo, David. Sync or Swarm: Improvising Music in a Complex Age. New York: Continuum, 2005.

6. Burkitt, Ian. Social Selves: Theories of the Social Formation of Personality. London: Sage, 1991.

7. Burrows, Jared B. "Musical Archetypes and Collective Consciousness: Cognitive Distribution and Free Improvisation." Critical Studies in Improvisation. 1.1 (2004): 1-15. 
8. Butler, Judith. "Bodies That Matter." Feminist Theory and the Body: A Reader. Ed. Price \& Shildrick. New York and London: Routledge, 1999.

9. Chevigny, Paul. Gigs: Jazz and the Cabaret Laws in New York City. New York and London: Routledge, 1991.

10. Csikszentmihalyi, Mihalyi, and Grant Rich. "Musical Improvisation: A Systems Approach." Creativity in Performance. Ed. R. Keith Sawyer. Greenwich \& London: Ablex, 1997. 43-94.

11. Dean, Roger T. New Structures in Jazz and Improvised Music Since 1960. Philadelphia: Open UP, 1992.

12. Fast, Susan. In the Houses of the Holy: Led Zeppelin and the Power of Rock Music. Oxford \& New York: Oxford UP, 2001.

13. Frith, Simon. "Music and Identity." Ed. Hall, Stuart and Paul du Gay. Questions of Cultural Identity. London: Sage, 1996. 108-127.

14. Heble, Ajay. Landing on the Wrong Note: Jazz, Disssonance, and Critical Practice. New York and London: Routledge, 2000.

15. Iyer, Vijay. "Exploding the Narrative in Jazz Improvisation." Uptown Conversation. Ed. O'Meally et al. New York: Columbia UP, 2004. 393-403.

16. Keil, Charles and Steven Feld. Music Grooves. Chicago \& London: U of Chicago P, 1994.

17. Lewis, George E. "Improvised Music after 1950: Afrological and Eurological Perspectives." The Other Side of Nowhere: Jazz, Improvisation, and Communities in Dialogue. Ed. Fischlin, Daniel and Ajay Heble. Middletown: Wesleyan UP, 2004. 131-162.

18. Monson, Ingrid. "What's Sound Got to Do With It? Jazz, Poststructuralism, and the Construction of Cultural Meaning." Creativity in Performance. Ed. R. Keith Sawyer. Greenwich \& London: Ablex, 1997. 95-112.
19. Panish, John. The Color of Jazz: Race and Representation in Postwar American Culture. Jackson: Mississippi UP, 1997.

20. Qureshi, Regula Burckhardt. "Musical Sound and Contextual Input: A Performance Model for Musical Analysis." Ethnomusicology 31 (1987): 56-86.

21. Reason, "Dana. "Navigable Structures and Transforming Mirrors': Improvisation and Interactivity." The Other Side of Nowhere: Jazz, Improvisation, and Communities in Dialogue. Ed. Fischlin, Daniel and Ajay Heble. Middletown: Wesleyan UP, 2004. 71- 83.

22. Sorbara, Joe. Personal Interview. 25 Mar. 2008.

23. Sarath, Ed. "A New Look at Improvisation." Journal of Music Theory 40 (1996): 1-38.

24. Sawyer, R. Keith. Group Creativity: Music, Theatre, Collaboration. Mahwah \& London: Lawrence Erlbaum, 2003.

25. Thomson, Scott and Michael Keith. Personal Interview. 19 Feb. 2008.

26. Zorn, John. Ed. Arcana: Musicians on Music. Granary Books: New York, 2000.

27. "Improvisation and the Creative Process: Dewey, Collingwood, and the Aesthetics of Spontaneity." The Journal of Aesthetics and Art Criticism 58 (2000): 149161.

28. "Improvisational Theater: An Ethnography of Conversational Practice." Creativity in Performance. Ed. R. Keith Sawyer. Greenwich \& London: Ablex, 1997. 171-193.

29. Saying Something: Jazz Improvisation and Interaction. Chicago and London: U of Chicago P, 1996. 